\title{
ONR special issue on multiphysics problems of marine composites
}

\author{
Yapa D. S. Rajapakse ${ }^{1}$ Young Kwon ${ }^{2}$
}

Published online: 31 July 2018

(c) This is a U.S. government work and its text is not subject to copyright protection in the United States; however, its text may be subject to foreign copyright protection 2018

Composite materials and structures have been used increasingly in marine applications. The marine environment provides unique conditions such as fluid-structure interactions, moisture and sea-water effects, temperature extremes, biofouling, etc.

Two special issues were completed on the topic "Composite Materials and Structures for Marine Applications". This issue focused on multiphysics problems of composite structures. Six papers were included in this special issue.

The first paper deals with research on repeated impact loading on woven composite structures under Arctic conditions (such as at $-50{ }^{\circ} \mathrm{C}$ ) until failure of the structure. The second paper examined the geometric scaling effect of implosions of composite tubes using a unique experimental test setup. The next article presented an experimental technique to measure internal deformations of a 3D body using the digital volumetric speckle photography technique. The fourth paper investigated blast resilience of hybrid composite panels with different combinations of glass-fiber and carbonfiber composites. Finally, the last two papers contain research on experimental studies to understand the fluid-structure interaction of composite structures. One dealt with structural coupling by fluid media, while the other discussed flowinduced vibration of a structure.

Publisher's Note Springer Nature remains neutral with regard to jurisdictional claims in published maps and institutional affiliations.
Young Kwon

ywkwon2004@yahoo.com

Office of Naval Research, Arlington, USA

2 Naval Postgraduate School, Monterey, USA 